
\title{
A Real-Time Integrated Fire Detection and Alarm (FDA) System for Network Based Building Automation
}

\author{
Farhat Anwar', Rounakul Islam Boby', Sabahat Hussain², Muhammad Mahbubur Rashid ${ }^{3}$ and \\ Zuhaib Shaikh ${ }^{3}$ \\ 'Kulliyyah of Engineering, International Islamic University Malaysia, 53100, Gombak, Kuala Lumpur, Malaysia; \\ farhat@iium.edu.my, rounakul.islam@live.iium.edu.my \\ ${ }^{2}$ Kulliyyah of Electronic and Computer Engineering, International Islamic University Malaysia, 53100, Gombak, \\ Kuala Lumpur, Malaysia; sabahathussain903@gmail.com \\ ${ }^{3}$ Kulliyyah of Mechanical Engineering, International Islamic University Malaysia, 53100, Gombak, Kuala Lumpur, \\ Malaysia; mahbub@iium.edu.my, zuhaibshaikh@hotmail.com
}

\begin{abstract}
Objectives: An integrated Fire Detection and Alarm (FDA) systems with building automation was studied, to reduce cost and improve their reliability by preventing false alarm, signal drop and network breakdown. This work proposes an improved framework for FDA system to ensure a robust, intelligent network of FDA control panels in real-time. Methods/ Analysis: In this work, the shortest path algorithm was chosen for series of buildings connected by a fiber-optic network. The framework shares information through the algorithm and communicates with each fire alarm panels connected in peer to peer configuration to declare the network state in every second using network address. The declaration from every building connected to the same network appears on Central Control Room (CCR) for real-time monitoring. Findings: The proposed FDA system is different from traditional fire alarm and detection system regarding topology as it manages a group of buildings optimally and efficiently. The single mode fiber-optic connectivity was introduced to reduce signal noises, thus increasing large area coverage and long-term safety. Also, the distributed peer to peer network was proposed to ensure fire survivability where the information is sequentially transmitted. Based on this proposed method a prototype system was designed to validate the performance, where the prototype showed a positive response concerning time consumption and real-time monitoring process than traditional. Improvement: The proposed FDA system got improvement, by consistent network state monitoring framework, fast, reliable connectivity with variable changes possibility and easy maintenance process for increasing robustness and intelligence.
\end{abstract}

Keywords: Framework, Fire Detection and Alarm (FDA), Real-Time, Reliability, Robustness and Intelligence

\section{Introduction}

Fire detection process for trading and housing places is a primary requirement to reduce destruction of personal property due to fire incident both natural and induced. Combining the network with controller approach, an innovative improvement has been made in building automation. The real-time surveillance system not only monitors the building automation ministrations but also control the FDMS by gathering, observing and storing related information. Among the fundamental technologies, networking had been used for improved building automation controller construction. Research notes that the concept of networking based controller used in many building automation processes is more efficient in fire detection and protection ${ }^{1-3}$.

${ }^{*}$ Author for correspondence 
It has been pointed out that the integration of networking, detection modules, sensors and a server work as a system to transmit data for fire detection. The communication method of exchanging information takes place via a digital communication medium. The exclusive design of the detectors spots the specific region of the fire effortlessly. Also, the workstations are organized to monitor the fire detectors at regular intervals to estimate any repair needed in the system. Most of the network-based fire detection systems are recently manufactured and traded with their proprietary network protocols $s^{4-6}$.

The design criteria of any fire alarm systems should differentiate between a false and genuine alarm, allowing quick rescue and implementing proper evacuation process, thus aiding the fire defenders. Furthermore, the fire alarm system should have the ability to reduce energy intake, in comparison with the existing systems. Hence, an intelligent fire system is required. These innovations will make up new openings and occasions in marketing fields for fire detection, safety and alarm systems $s^{7-8}$. The researchers also designed fire detection system unified with smoke detection sensors, health monitoring devices, a display module, wireless communication modules, multi detectors sensors, indirect approach through networking module, temperature sensors and linerheat-sequences tracking system. The central ideology to combine these techniques is to develop trustworthiness, reduce the occurrence of a false alarm, discriminate between a natural and induced fire smokes and most importantly increase the life of property by fire protection systems. The conventional fire detection system requires much improvement and plenty of research nowadays to increase detection sensitivity of any sign of smoke in a particular area ${ }^{9-11}$. Similarly, the cost-effective sensor network system has more advantages than conventional to enhance durability and reliability of an intelligent automation system ${ }^{12-13}$.

A system has also been developed with wireless sensor based neural-network for fire detection. The neural-network was used to increase the life expectancy of the network. The researchers used simulation process to show the performance ${ }^{14}$. They also validate that the simulation process is effective to reduce communications between sensor nodes. Another research group developed grey-fuzzy controller based neural-network to detect the fire detection in the Tibet region. The design was drawn up to monitor signal values of fire detection sensors to calculate the value of smoke, temperature and $\mathrm{CO}_{2}$ den- sity in the air during the detection period, where the 30 seconds delay detection technique was used. Finally, the data was used as prediction result input to ANFIS system to determine the detecting probability ${ }^{15}$. A communication network of a system was proposed to extend by an intermediate-layer or dependability layer. The layer should be transparent to operate on a seamless intricated network. Thus, the group addressed reliability in terms of fault tolerance. They offered a redundant network in the system and named as heartbeat mechanism where the system acknowledgment and particular message format will hold the safety requirements $\frac{16}{16}$. A Network feedback based Internet Of Things (IOT) system and method was proposed for home and small business. The primary motive was to connect, control and monitor more than one appliance together. The proposed method is used to understand electrical consumption, make decisions on fault detection, prompt to save energy, up-gradation of the system, Internet-based monitoring and alarm for the system as well as prevention of device over-heated or frozen, damaged device detection, the possibility of fire losses and loss of life. The proposed system also includes Internet communication-based software and data communication, hardware interfaces on safety issue in communication line and optional wireless outlet ${ }^{17}$.

A stand-alone security system was transformed into an intelligent network based on a computer-controlled automatic building automation system. The purpose of the research was to design a pilot model for security using wired network technology. A web-based virtual instrument was introduced to monitor and control the base from a long distance. It was claimed that they could be re-usable with little customization and increase some more nodes. Though the system shows more potential, it is not reliable in the long run because of maintenance and non-automatic plug and play service $\frac{18}{}$. Another research group proposed node detection wirelessly using FPGA based management. It was a Zigbee technology using LabVIEW software. LabVIEW developed FPGAs are used for the high-performance system, where this system will be highly reliable ${ }^{19}$. An intelligent alarm system was designed with photoelectric materials to detect smoke and temperature. The system uses AT89C51 unit as the hardware control and monitoring. The controller unit converts the analog signal to digital signals and produces machine output. The system is simple and inexpensive ${ }^{20}$. Wireless Sensor Network for FDS also became more popular because detection message will 
be delivered through wireless sensors. The wireless sensor nodes include catalytic gas sensors, controller and wireless transceiver using BACnet protocol but the weakness is noise and false alarm. To overcome this problem Controller Area Network (CAN) was developed through a radio protocol known as wireless protocol ${ }^{21-23}$. A system was designed to reduce the false alarm in the train. Smart sensors and microcontroller developed the system. It will automatically detect fire and use the mobile network to share information. The nodes use pattern matching system where a predefined set of rules were used as the packet of traffic. To reduce false alarm, the signals are reanalyzed with the predefined packet of traffic and detect the signal as bad traffic. But, the main drawback of the network is that the ratio of the false alarm depends on the performance of detection engine. To reduce this problem, signature-based traffic method was developed 4 24-25.

The researchers also developed UV and infrared stereo vision sensors to detect fire in low visibility range. These sensors can be used for long-term fire detection system using 3D coordination effect of fire. Visual servo system was used to target the fire location and place the suppuration module towards the fire to remove fire immediately. The system perfectly worked on visibility condition of 1.62 meters. The surrounding environment was developed with simulated wind and smoke effect ${ }^{26}$. A probabilistic classification method was developed using thermal detection method. The algorithm automatically locates fires by a thermal imaging technique, where visibility is zero. This algorithm was also established through test dataset ${ }^{27}$. Again, a signal traffic management system for FDS was proposed for smart cities where a robust fire detection method was proposed using dictionary method. The method computes each patch using linear SVM ${ }^{28-31}$. Optical fiber sensors are proven to be used in industrial applications because of long durability. Conventional distributed sensors performance is exploited through optical sensors because of fire detection exceptional resolution. The sensors can detect long distance with higher accuracy $^{32}$. A distribution network using optical fiber for close room environment is highly effective for fire detection system. The problem of this sensor was that it could work only in a closed chamber. Though, the method demonstrated that it represents a robust and reliable technique to localize the fireplace ${ }^{33-34}$. The communication system for fire detection system should be more reliable and durable. The system will be a bi-directional high speed distribution network, and the data will be carried out through data bus signal $\frac{35-40}{}$. For optical fiber network, all possible network combination is suitable because of high data transfer rate. In the next generation all network architecture designing on an optical fiber, however, P2P network are different from each other ${ }^{41-43}$. For Active Optical Network (AON) and wavelength division multiplexing passive optical network (WDM PON) fiber is the best choice. Even future $5 \mathrm{G}$ networks are designing on fiber network due to the data transfer capacity. Also, cloud-based network excess relay on optical fiber network $\frac{44-47}{}$.

The proposed framework of powerful fire alarm detection system depends upon Ring Topology. In this work, the focus is set to develop an efficient fire alarm detection system, applying a topology which depends on the algorithmic approach. This framework enlightens currently available process of powerful fire detection system by minimizing the time to activate an alarm system. Moreover, by integrating the FDA system into the buildings, it will allow the system to react to variations in real time, thus able to generate alarm during the state of an emergency.

\section{Network-Based Fire Detection System}

It is known that many existing technologies have been implemented in the past for effective fire detection system in a real-time environment which faces a significant drawback in the transmission of data over a considerable distance. A long-distance data transmission using normal communication cable can lead to a drop-in signal, hence making it inconvenient for long distance data transfer. If all the different buildings are made to connect to one network, and by implementing a suitable network topology, that will be able to take the shortest path to transmit the monitored data, then the stability of the system can be enhanced. The network topology selected in this work is based on the prime interest which is being able to connect different buildings in one network. From many available network topologies like bus topology, star topology, ring topology, mesh topology, tree topology, and hybrid topology, we have chosen the ring topology. In this situations as compared to others, since communication between long distance is the key factor in this work. The inter-building communication is usually done using communication cable where signals tend to drop significantly over long distance data transfer. Figure 1 shows a typical ring net- 
work topology setup. Here, a token or a tiny data packet is transmitted over the network, and whenever there is a need to send a data packet, the device keeps the token for the next trip around and fixes its data packet to it. This setup makes it extremely easy to manage the peer to peer network. While the transmission is intended for a short distance, an efficient and high-quality communication is ensured. This setup is perfectly suitable to handle the traffic of high volume in short distance. Furthermore, the ring topology uses dual rings as a backup in case of one link failure with less wiring.

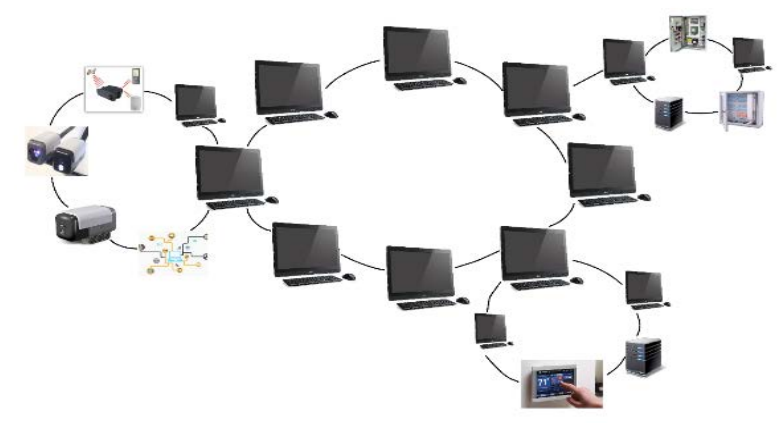

Figure 1. Ring topology setup.

\section{Proposed Algorithmic Approach to Fire Alarm Detection System}

To upgrade the capability of currently running fire detection and alarm system for long distance, this algorithm was proposed for reducing noise and signal drop problem while delivering an authentic alarm in the network. Optical fiber and optical module were proposed in building nodes where internal sensors connection will be the same with regular network cables. By using optical network procedure during a crucial time, the fire affected buildings could be saved with minimum losses. A prototype simulation model system, based on the real-world situation (having the same parameters) was implemented / designed for fire detection system and fire alarm, as like, the FDA system screens sequence of buildings in a restricted area, such as in the industrial environment, some buildings located closely in an area. All the buildings and CCR was connected to each other through a ring network.

The framework would share the information in a peer to peer method, connecting the remotely situated control panels. To supply an alarm signal and give proclamation of fire state, the panel connected in the network would produce alarm signal on network state to send information to the other panels or CCR. Because of signal analysis and signal conversion it may few times, but the real-time communication time depends on the number of connected building nodes. Considering this problem, the framework will work on shortage path calculation and proclaim its fire state to CCR. Again, if the communication is somehow interrupted the longest path will be considered. The shared information works gradually from one building to another. Figure 2 illustrates the flowchart of the algorithm used in this work.

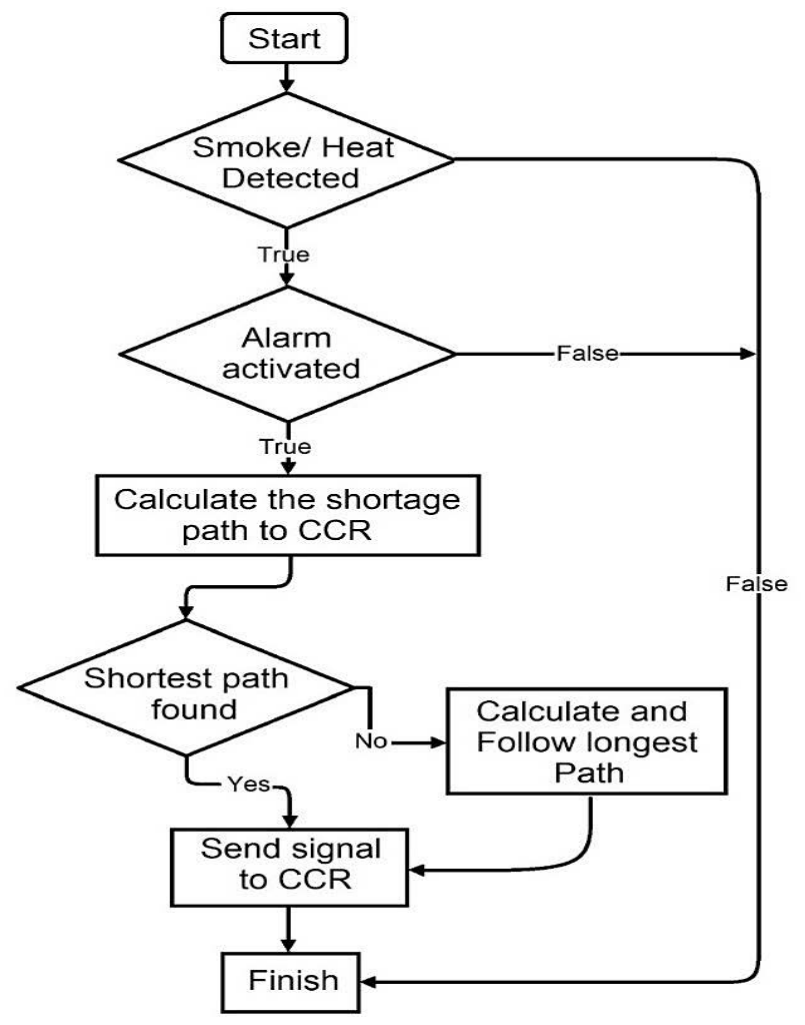

Figure 2. Flowchart of the proposed algorithm.

In this following section, it is explained how the least and highest time is calculated in a building during a fire incident for different scenarios. The work conducted is intending to use three building blocks. Blocks A, B, and $C$ are assumed to be situated in an industrial area. Each block is surrounded by six other buildings within a distance of 500 meters Figure 3, fire alarm panels are affiliated to fiber optic converter to form ring topology when all buildings are joined in a group. The management of transmission between the buildings is made effortless through ring-based approach. 


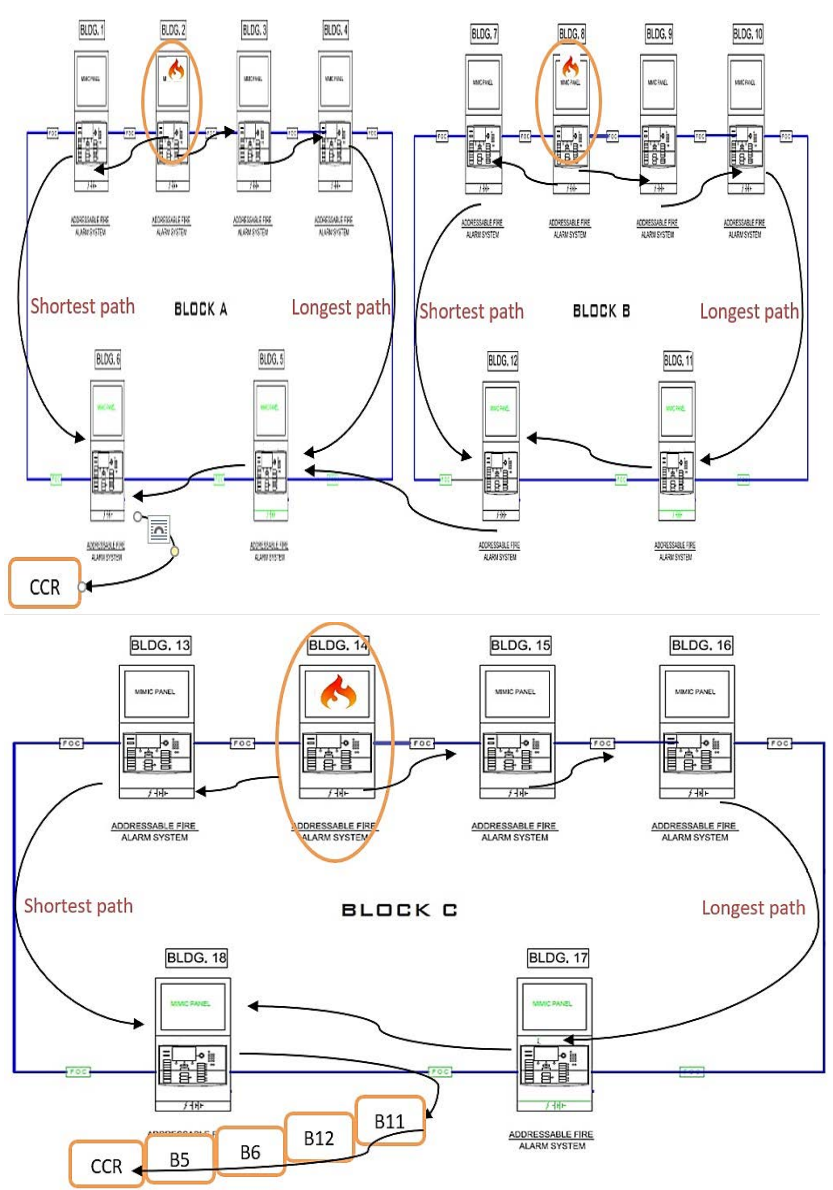

Figure 3. Projected network topology for the buildings with the CCR and fire rescue department (Bomba Station) including Block A, Block B, and Block C.

The Block-A consist of building number 1, 2, 3, 4, 5 and 6. Similarly, Block B and $C$ include building numbers $7,8,9,10,11,12$ and $13,14,15,16,17,18$ respectively. These blocks are connected with Gytc8s single optical fiber 8-layer outdoor cable and its respective signal conversion module. The inter-block ring network also can work if any inter-block connection failure happens, and the signal will flow through any short or long possible way.

The buildings 5 and 6,11 and 12, 17 and 18 were contacted in same network fashion by Gytc8s outdoor use cable to share information in CCR loop network. The reason for selecting these buildings to be connected with the core is that they would have the shortest distance from the central control building and the fire rescue department in the network.

The core communication line connects control units and fire rescue department with rest of buildings in the block. Building 6 in block $\mathrm{A}$ is in most immediate reach to the control unit. And for the fire rescue department, it is 17. The distance of the control unit from the fire rescue department is about 500 meters as shown in Figure 3. The fire alarm situation in the network is observed and monitored through communication among each other. They maintain contact with other buildings in blocks through Ethernet switch by using CATE STP cable. The function of the CCR and fire rescue department is to supervise and regulate the communication. On the contrary when either CCR or fire rescue department is deviated from its function due to certain circumstances then still one can control it by alternative ways.

Further, information can be sent or received among each other. This makes a more persistent connection between the topology of building and these control units. Under worst events where both control units fail, the buildings connected in a loop network can work as standalone network and during fire detection the loop network can perform their operation individually by switching local alarm or visual devices, sending information through passive proclamation gadgets, releasing the magnetic lock, AHU management, governing of sprinkler and elevator alarm declaration activation, releasing relatively non-secure door links, switching gas control unit, closing the highly secure area those are far away from fire detection place, $\mathrm{CO} 2$ gas unit interfacing and switching the main power module to off, etc. Results analysis of Proposed Algorithm

In this work, JAVA script was used for coding and execution of the algorithm. Where building distances were considered as $500 \mathrm{~meter} /$ building, and the system response of the FDA panels are considered as is. The coding followed the proposed algorithmic way by considering these parameters. The results of shortest and longest paths are discussed. Case Scenario-1

A case scenario is taken to understand, how the proposed FDA system works. It was assumed that building 2 caught fire in Block A as shown in. 3, shortest time taken for sending a signal to control room would be through building 1 to 6 to CCR.

In the same way, only using building 3 the longest path can send information to CCR. The short and long paths results are shown in Table 1 and 2 respectively. It is evident that the longest path (B2, B3, B4, B5, B6, and CCR) consumes more time than shortest path (B2, B1, B6, and CCR). The topology of buildings frames out the reason behind the shortest path. 
Table 1. Summary of the important research developments

\begin{tabular}{|c|c|c|c|}
\hline Methods & Years & Advantages & Disadvantages \\
\hline $\begin{array}{l}\text { Network feedback } \\
\text { based IOT }\end{array}$ & 2014 & $\begin{array}{l}\text { 1. connect, control and monitor more } \\
\text { than one appliances together through IoT. }\end{array}$ & $\begin{array}{l}\text { 1. Constant monitoring and services are } \\
\text { required. }\end{array}$ \\
\hline $\begin{array}{l}\text { Wired Building } \\
\text { Automation }\end{array}$ & 2015 & $\begin{array}{l}\text { 1. pilot models with the wired network. } \\
\text { 2. Web-based instrument. }\end{array}$ & $\begin{array}{l}\text { 1. Maintenance required. } \\
\text { 2. Automatic nodal updates not possible. }\end{array}$ \\
\hline $\begin{array}{l}\text { Network-based FDS } \\
\text { via CAN }\end{array}$ & 2004 & $\begin{array}{l}\text { 1. Very short response time. } \\
\text { 2. Direct data accusation for accuracy. }\end{array}$ & $\begin{array}{l}\text { 1. Data received directly from the fire } \\
\text { detectors any interruption means system loss. }\end{array}$ \\
\hline $\begin{array}{l}\text { FPGA based smart } \\
\text { system. }\end{array}$ & 2016 & $\begin{array}{l}\text { 1. Smart system. } \\
\text { 2. Auto update. }\end{array}$ & 1. Use for a stand-alone system. \\
\hline BACnet-based FDS & 2014 & $\begin{array}{l}\text { 1. Monitoring system using MS/TP } \\
\text { protocol. } \\
\text { 2. reference model is operated by wireless- } \\
\text { BACnet for flexibility. }\end{array}$ & $\begin{array}{l}\text { 1. Signal is directly dependent upon the traffic } \\
\text { load. } \\
\text { 2. Inter-operability of different vendors' field } \\
\text { devices makes problems. }\end{array}$ \\
\hline Addressable FACS & 2015 & $\begin{array}{l}\text { 1. Broad range of device connecting } \\
\text { capabilities. }\end{array}$ & 1. Standard capacity of maximum 127 points. \\
\hline $\begin{array}{l}\text { Dedicated Computer } \\
\text { Controlled system }\end{array}$ & 2016 & $\begin{array}{l}\text { 1. Added power, Internet connectivity, } \\
\text { and remote service capabilities }\end{array}$ & $\begin{array}{l}\text { 1. Failure of dedicated computer or } \\
\text { connection problem can fail the system. } \\
\text { 2. Required maintenance. }\end{array}$ \\
\hline $\begin{array}{l}\text { Address-able VAD } \\
\text { (Visual Alarm Device) }\end{array}$ & 2010 & 1. Visual Alarm Device. & $\begin{array}{l}\text { 1. For a small plant. } \\
\text { 2. Extension not possible. }\end{array}$ \\
\hline $\begin{array}{l}\text { Pattern matching } \\
\text { process }\end{array}$ & 2015 & $\begin{array}{l}\text { 1. Use predefined pattern matching } \\
\text { process. } \\
\text { 2. Signature-based traffic. }\end{array}$ & $\begin{array}{l}\text { 1. The performance depends on detection } \\
\text { engine. }\end{array}$ \\
\hline Mechatronic approach & 2016 & $\begin{array}{l}\text { 1. Autonomous fire-suppression module } \\
\text { was used. } \\
\text { 2. Versatile device addable. }\end{array}$ & 1. The autonomous system used is expensive. \\
\hline Optical fiber sensors & 2014 & $\begin{array}{l}\text { 1. Long durability. } \\
\text { 2. Long distance detection. }\end{array}$ & 1. The problem of hot air. \\
\hline
\end{tabular}

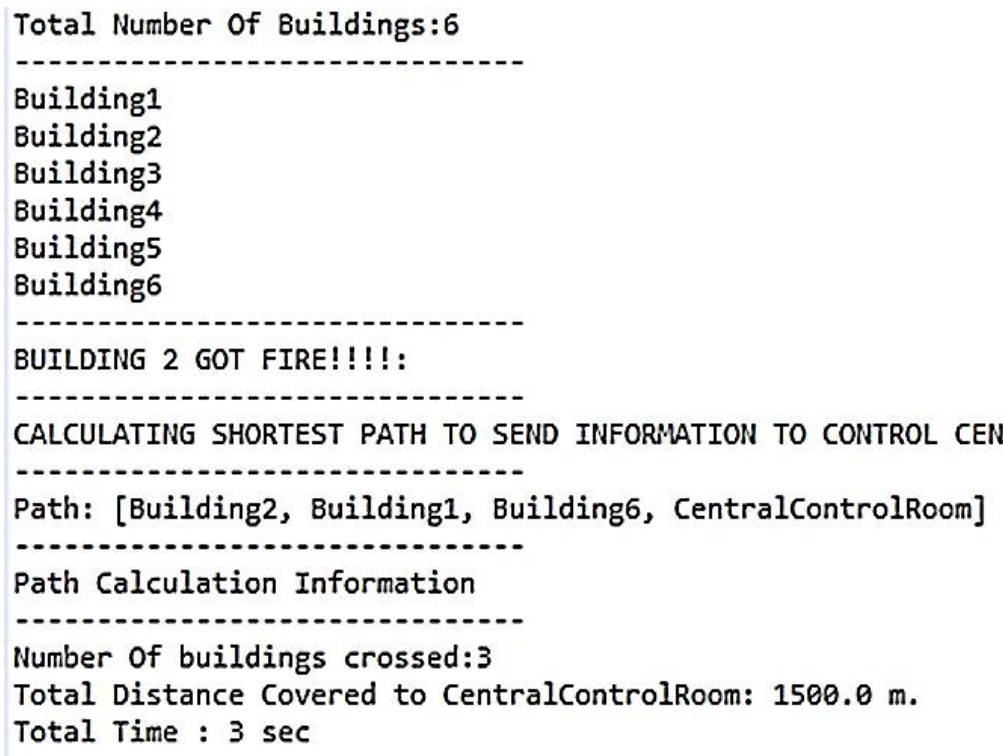

Figure 4. Receiving signal from building no.2 through shortest path to the CCR. 
Table 2. The time and other parameters calculation of shortest path results in block-A

\begin{tabular}{|l|l|l|l|l|l|}
\hline No. of Paths & $\begin{array}{l}\text { Building } \\
\text { Under Fire }\end{array}$ & $\begin{array}{l}\text { Shortest Path To } \\
\text { CCR }\end{array}$ & $\begin{array}{l}\text { Distance Covered } \\
\text { to CCR (Meter) }\end{array}$ & $\begin{array}{l}\text { Time to Reach } \\
\text { Signal (Second) }\end{array}$ & $\begin{array}{l}\text { No. of Buildings } \\
\text { Crossed }\end{array}$ \\
\hline 1 & B2 & B2, B1, B6 \& CCR & 1500 & 3 & 3 \\
\hline
\end{tabular}

Table 3. The time and other parameters calculation of longest results in block-A

\begin{tabular}{|l|l|l|l|l|l|}
\hline $\begin{array}{l}\text { No. of } \\
\text { Paths }\end{array}$ & $\begin{array}{l}\text { Building } \\
\text { Under Fire }\end{array}$ & $\begin{array}{l}\text { Shortest Path } \\
\text { To CCR }\end{array}$ & $\begin{array}{l}\text { Distance Covered } \\
\text { to CCR (Meter) }\end{array}$ & $\begin{array}{l}\text { Time to Reach } \\
\text { Signal (Second) }\end{array}$ & $\begin{array}{l}\text { No. of Buildings } \\
\text { Crossed }\end{array}$ \\
\hline 2 & B2 & $\begin{array}{l}\text { B2, B3, B4, B5, } \\
\text { B6 \& CCR }\end{array}$ & 2500 & 5 & 5 \\
\hline
\end{tabular}

Table 4. The time and other parameters calculation of shortest path results of building 8, block B.

\begin{tabular}{|l|l|l|l|l|l|}
\hline $\begin{array}{l}\text { No. of } \\
\text { Paths }\end{array}$ & $\begin{array}{l}\text { Building } \\
\text { Under Fire }\end{array}$ & $\begin{array}{l}\text { Shortest Path } \\
\text { To CCR }\end{array}$ & $\begin{array}{l}\text { Distance Covered } \\
\text { to CCR (Meter) }\end{array}$ & $\begin{array}{l}\text { Time to Reach } \\
\text { Signal (Second) }\end{array}$ & $\begin{array}{l}\text { No. of Buildings } \\
\text { Crossed }\end{array}$ \\
\hline 1 & B8 & $\begin{array}{l}\text { B8, B7, B12, } \\
\text { B5, B6 \& CCR }\end{array}$ & 2500 & 5 & 5 \\
\hline
\end{tabular}

Table 5. The time and other parameters calculation of Longest results for building 8, in block-B.

\begin{tabular}{|l|l|l|l|l|l|}
\hline $\begin{array}{l}\text { No. of } \\
\text { Paths }\end{array}$ & $\begin{array}{l}\text { Building } \\
\text { Under Fire }\end{array}$ & $\begin{array}{l}\text { Shortest Path } \\
\text { To CCR }\end{array}$ & $\begin{array}{l}\text { Distance Covered } \\
\text { to CCR (Meter) }\end{array}$ & $\begin{array}{l}\text { Time to Reach } \\
\text { Signal (Second) }\end{array}$ & $\begin{array}{l}\text { No. of Buildings } \\
\text { Crossed }\end{array}$ \\
\hline 2 & B8 & $\begin{array}{l}\text { B8, B9, B10, } \\
\text { B11, B12, B5, B6 } \\
\text { \& CCR }\end{array}$ & 3500 & 7 & 7 \\
\hline
\end{tabular}

Total Number of Buildings: 6
Building1
Building2
Building3
Building4
Building5
Building6

BUILOING 2 GOT FIRE!!!!!:

CALCULATING LONGEST PATH TO SEND INFORMATION TO CONTROL CENTER:

Path: [Building2, Building3, Building4, Building5, Building6, CentralControlRoom]

Path Calculation Information

Number of buildings crossed: 5

Total Distance Covered to CentralControlRoom: $2500.0 \mathrm{~m}$.

Total Time : 5 sec

Figure 5. Receiving signal from building no.2 through the longest path to the CCR. 
Total Number of Buildings: 8

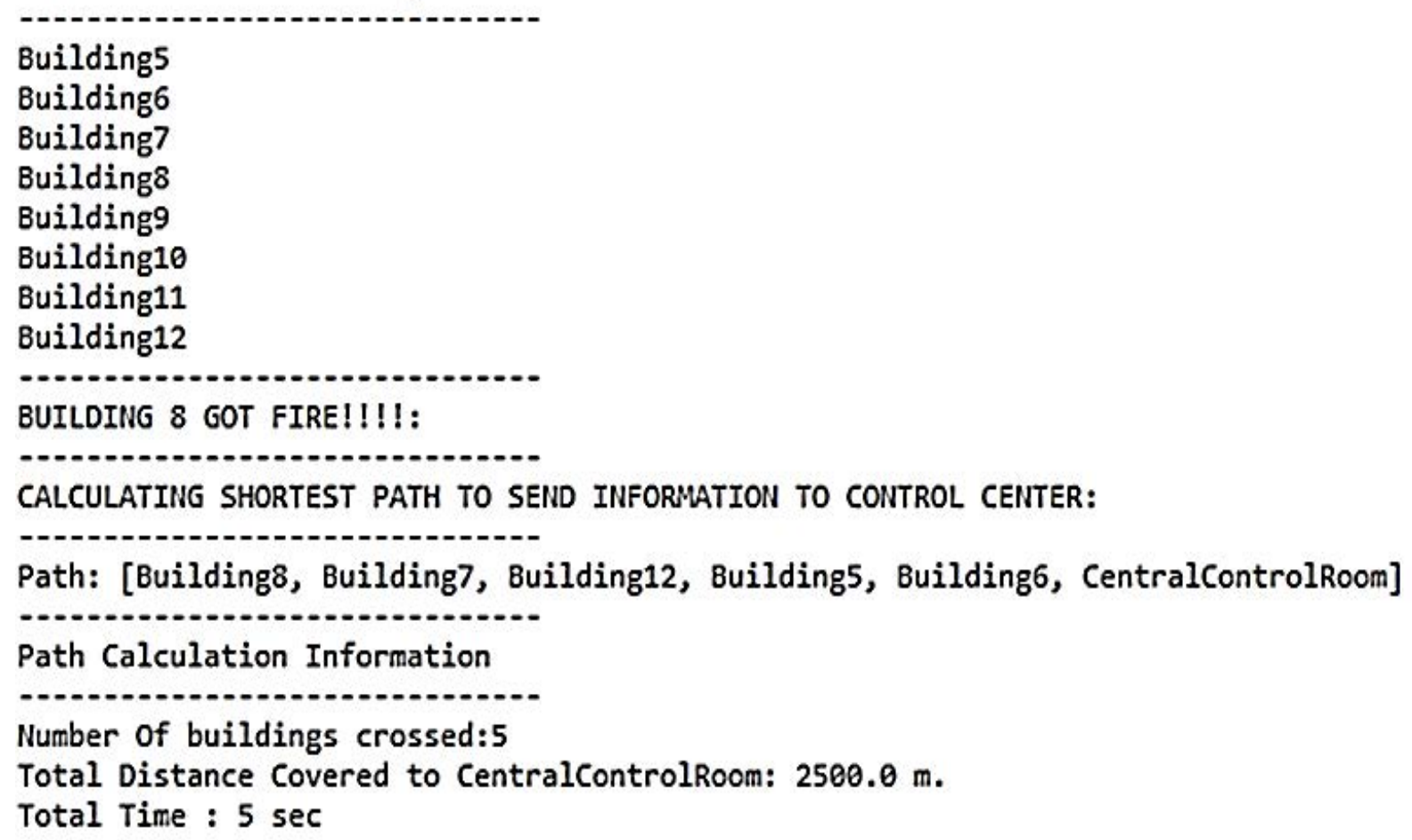

Figure 6. Receiving signal from building no.8 through shortest path to communicate with the CCR.

Total Number of Buildings: 8

Building5
Building6
Building7
Building8
Building9
Building10
Building11
Building12

BUILDING 8 GOT FIRE!!!!:

CALCULATING LONGEST PATH TO SEND INFORMATION TO CONTROL CENTER:

Path: [Building8, Building9, Building10, Building11, Building12, Building5, Building6, CentralControlRoom] .................................................

Path Calculation Information

Pa...................................................

Number of buildings crossed:7

Total Distance Covered to CentralControlRoom: $3500.0 \mathrm{~m}$.

Total Time : $7 \mathrm{sec}$

Figure 7. Receiving signal from building no.8 through the longest path to the Central Control room. 


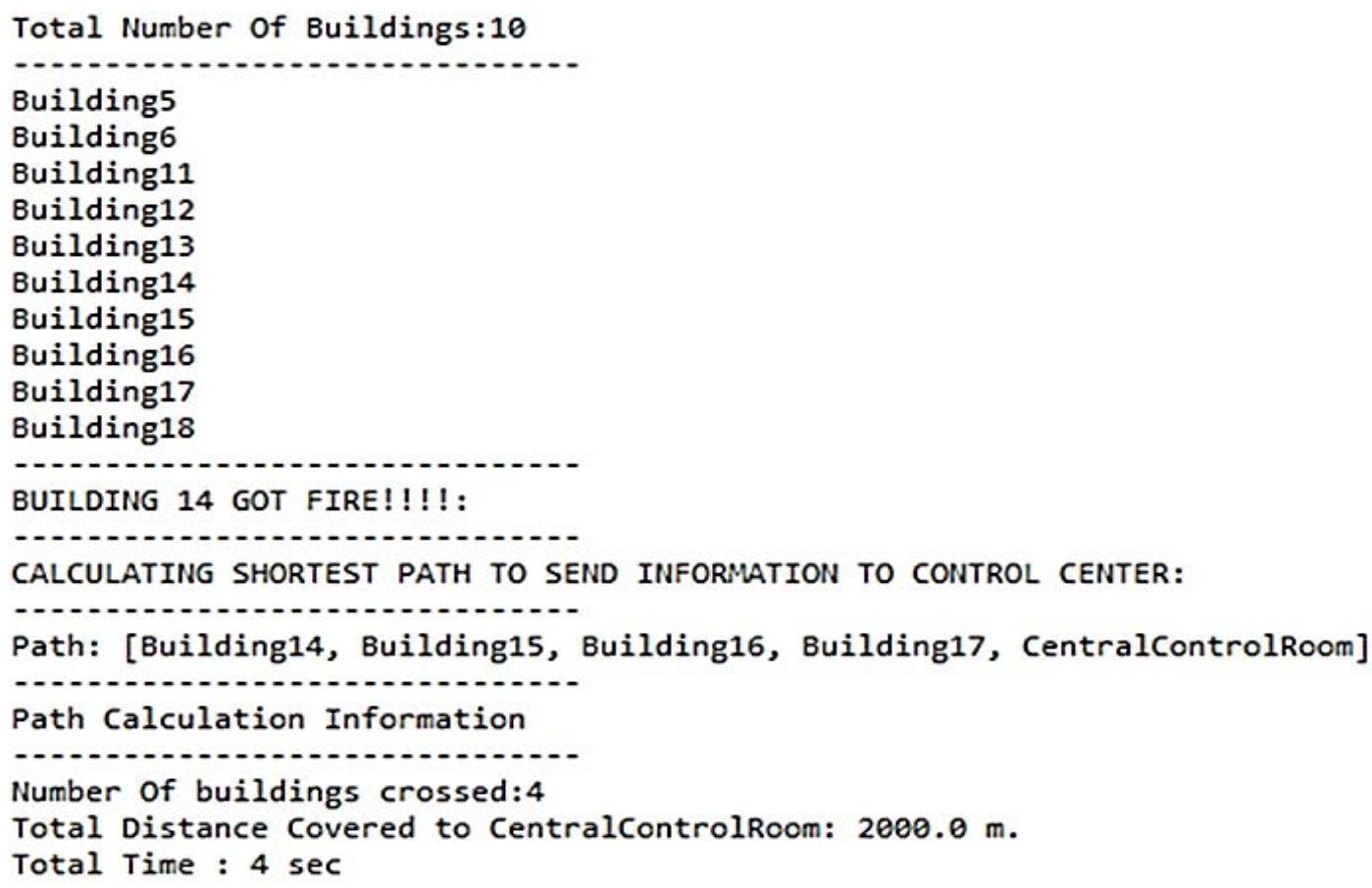

Figure 8. Building no. 14 sending signal to CCR through shortest path.

Table 6. Show the time and other parameters calculation of shortest path results in block C

\begin{tabular}{|l|l|l|l|l|l|}
\hline $\begin{array}{l}\text { No. of } \\
\text { Paths }\end{array}$ & $\begin{array}{l}\text { Building } \\
\text { Under Fire }\end{array}$ & Shortest Path To CCR & $\begin{array}{l}\text { Distance Covered } \\
\text { to CCR (Meter) }\end{array}$ & $\begin{array}{l}\text { Time to Reach } \\
\text { Signal (Second) }\end{array}$ & $\begin{array}{l}\text { No. of } \\
\text { Buildings } \\
\text { Crossed }\end{array}$ \\
\hline 1 & B14 & $\begin{array}{l}\text { B14,B15,B16,B17,BS\& } \\
\text { CCR }\end{array}$ & 2000 & 4 & 4 \\
\hline
\end{tabular}

\subsection{Case Scenario-1}

\subsubsection{Shortest Path for Case Scenario-1}

For shortest path calculation in block-A when building 2 catches fire, the shortest path has been found from the simulated program as a minimum number of buildings from affected building to control unit through B1 as shown in Table 2 and Figure 4. According to the program output, it took 3 seconds to reach control unit where only two buildings are crossed from source to destination.

\subsubsection{Longest Path for Case Scenario-1}

In the case of the longest path, the route from building B2 to CCR is through B3. Here the total distance covered is 2500 meters and time to reach the destination is 5 seconds as shown in Table 3 and Figure 5. The buildings crossed are 4 as compared to 2 in the shortest path. Here if shortest path is not feasible due to some reasons, then the communication can be completed by longest path.

\subsection{Case Scenario-2}

Let us suppose, building 8 caught fires in block-B as shown in Figure 3. The minimum time required for the signal from building 8 to CCR through building 7 and same way from 8 to CCR through building 9 can be estimated to find shortest and longest path. Shortest and longest paths results are shown in Table 4 and 5 and Figure 6 and 7 respectively.

\subsubsection{Shortest Path for Case Scenario-2}

In this case of block $\mathrm{B}$, if building 8 caught fire then the shortest path from B8 to CCR where it took 5 seconds to send signals to control unit. The total distance covered is 2500 meters, and the number of building crossed is 5, where this path is known as the shortest path. 


\subsubsection{Longest Path for Case Scenario-2}

For this case, if building 8 of block $B$ got fire then the longest path is from building 8 to CCR is through the building 9 shown in Table 5 and Figure 3 where it took 7 seconds to send signals to CCR. The total distance covered is 3500 meters, and the number of building crossed is 7. Again, the shortest and longest path depends on the predefined calculation. If a new building adds in the loop, the constant communication from the buildings to CCR will be newly calculated. If the signal from building buildings adds in the loop, the constant communication from the buildings to CCR will be newly calculated. If the signal from building 8 to CCR through building 9 became less, then this path will be automatically set up as the shortest path.

\subsection{Case Scenario-3}

Again, if Block-C building 14 caught fire, the possible time to send signals to the Control room is through build- ing 13, 18 to Bomba Control station. Similarly, another path to send information is through building 15 to 17 to CCR.

\subsubsection{Shortest Path for Case Scenario-3}

For the case- 3 the shortest path found from the building 14 to CCR through B13, B18, B17 and Bomba station shown in Figure 3. Again another shortest path can be accessed through B15, B16, B17 and Bomba station. In both shortest paths, the number of buildings passed is same. But the algorithm was following the second transmission way. The shortest path result of the paths is shown in Figure 8, and the result is given in Table 6.

\subsubsection{Longest Path for Case Scenario-3}

Again for the longest path can be found through B13, B18, B11, B12, B5, B6 and CCR. Where another logical paths can be accessed through B15, B16, B17, B18, B11, B12, B5, B6 \& CCR. But the automatic algorithm was following the

Table 7. Show the time and other parameters calculation of longest path in block C

\begin{tabular}{|l|l|l|l|l|l|}
\hline $\begin{array}{l}\text { No. of } \\
\text { Paths }\end{array}$ & $\begin{array}{l}\text { Building } \\
\text { Under Fire }\end{array}$ & $\begin{array}{l}\text { Shortest Path } \\
\text { To CCR }\end{array}$ & $\begin{array}{l}\text { Distance Covered } \\
\text { to CCR (Meter) }\end{array}$ & $\begin{array}{l}\text { Time to Reach } \\
\text { Signal (Second) }\end{array}$ & $\begin{array}{l}\text { No. of Buildings } \\
\text { Crossed }\end{array}$ \\
\hline 2 & B14 & $\begin{array}{l}\text { B14, B13, B18, } \\
\text { B11, B12, B5, B6 } \\
\text { \& CCR }\end{array}$ & 3500 & 7 & 7 \\
\hline
\end{tabular}

Total Number of Buildings:10

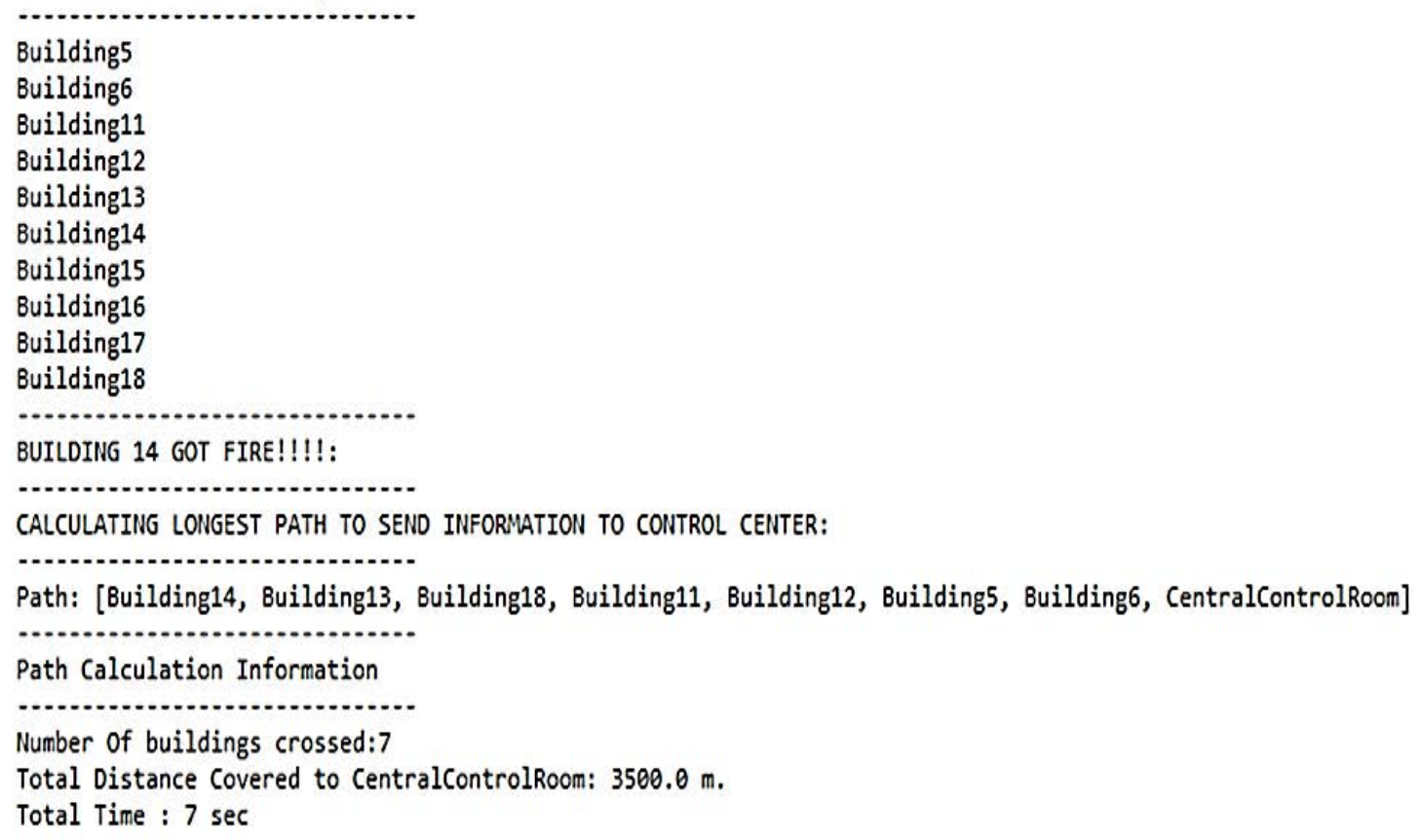

Figure 9. Building no. 14 sending signal to CCR through longest path. 


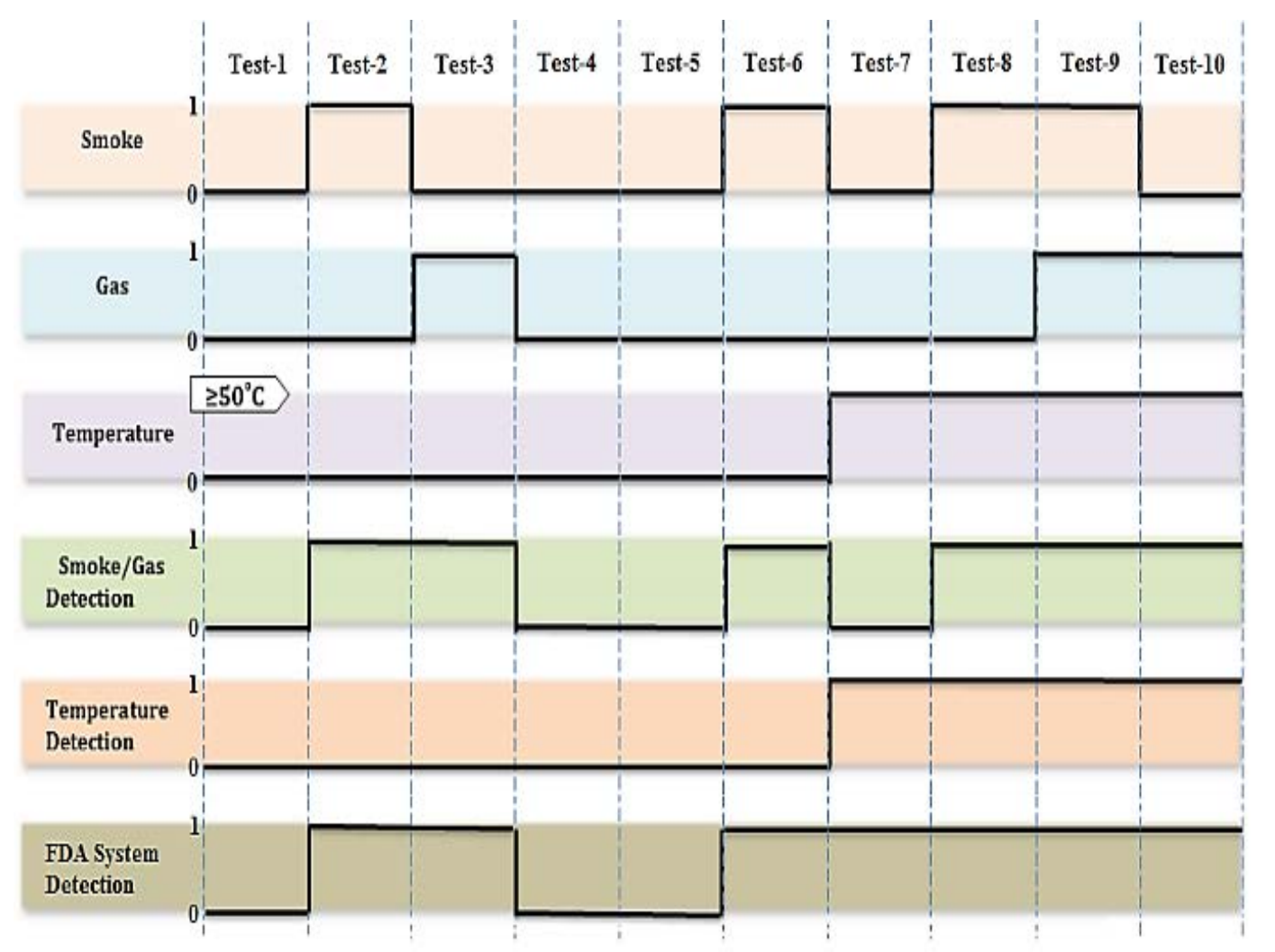

Figure 10. FDA response according to the sensors.

first way. The longest path took 7 seconds while the signal was traveling 3500 meters for the longest way. Though there is another longest way was available, the program would follow the same until an interrupt happens. The longest path result for the case- 3 is shown in Table 7 and Figure 9.

FDA signal detection in this system, all FAS have their own sensors network loop for a different building. In this separate circuit, the sensors are only transferring their valuable data to the corresponding FAS. The correspondent FAS then transfer the signals in its own block loops and following to the CCR-Bomba loops.

Single sensor detection if any FAS are not getting signals from any sensor, the FAS share its network state condition without alarm output. If any sensor gives a signal or constantly giving signals to the FAS, The corresponding FAS continuously update its network state with the alarm signal. In this system, the program is designed that the FAS will update its network state condition immediately fire is detected by the sensor. One of the same FAS signals condition for the sensors' detection shown in Figure 10 which we followed in this proposed system $^{48}$.
Multi-sensors detector though, the transmitted signals from the sensors are independent and depend on the sensor detection and also represent the detection level of the smoke and temperature of air in the room; the sensor controller processes the output signals automatically to send data to FAS. This proposed system is not focusing on sensor system but the signal processing of the sensor affecting the FDA signals for the addressable network. The multiple-sensor detection and the constant detection of a single sensor perform the same in this proposed system. The main advantage of this detection process is to simplify the system and immediately acknowledge the CCR. The signal condition of multiple-sensor detection is also same as the Figure $10^{49}$.

Network breakdown in this system, we proposed duplex communication port for single mode data transfer processing to detect shortest and longest path calculation with addressable FDA system. The advantages of this method are constant monitoring and a redundant signal path to secure the network from sudden breakdown and approaching for immediate troubleshooting. Necessarily, all the recent design of fire alarm and detection system for intelligent networking process are addressable sys- 
Table 8. Performance comparison of networking cables

\begin{tabular}{|c|c|c|c|c|c|}
\hline \multirow{2}{*}{ Connectivity } & \multirow{2}{*}{ Shield } & \multirow{2}{*}{ Installation } & \multicolumn{2}{|l|}{ Max TR distance } & \multirow{2}{*}{ Lifecycle } \\
\hline & & & (100BASE-FX) & (1000BASE-SX/LX) & \\
\hline Cat-5,5e,6,6a (UTP) & Un-shield & Indoor & $100 \mathrm{~m}$ & $33-50 \mathrm{~m}$ & 3-10 years ${ }^{51}$ \\
\hline Cat-6,6a,7(STP) & Shield & Indoor/Outdoor & $100 \mathrm{~m}$ & $55 \mathrm{~m}$ & $10-15$ years $^{51}$ \\
\hline $\begin{array}{l}\text { Optical fiber- } \\
\text { FDDI,OM1,OM2, } \\
\text { OM3,OM4 (S/M) }\end{array}$ & $\begin{array}{l}\text { Shield with } \\
12 \text {-standard }\end{array}$ & Indoor/Outdoor & $2000 \mathrm{~m}$ & $220-550 m$ & $20-25$ years $^{52}$ \\
\hline
\end{tabular}

tems, which can permit sensitive data to share with each of the detectors installed. This addressable network system has Drift Compensation process, also known as the self-calibration method. The advantages of this approach are adaptive device supervision, plug \& play installation and the ability of advanced troubleshooting ${ }^{50}$.

False Alarm and Signal Drop the benefits of this intelligent FAS are an adaptive algorithm, minimal wiring costs, addressable FAS, network integration and instant capability of fire identification process. If any signal interruption happens, immediately the building will be available through a redundant network, and in the worst case of scenario, if the building will not appear on the list, notification will come for immediate maintenance. In the case of false alarm, the network is free from twisted cable, thus no possibility of affected by thunders or electric shock. Table 8 shows the performance comparison of optical fiber over existing networking cables ${ }^{50}$. Again, because of addressable FAS, any false signal will be suppressed by the program if not contain any fixed address ${ }^{51-52}$.

Scalability the proposed network has an excellent scalability and adaptability on performance. This system is designed to add or remove any number of building FDA in the loop. Though every system should have a maximum capacity, the ability of proposed system can be estimated through calculation. In this system, we have found every FDA producing addressable data of 178bytes in every second for constant monitoring and the average data we have recorded $9.18 \mathrm{k}$ bytes for the shortest path and $17.6 \mathrm{k}$ bytes for the longest path in one hour. According to this recorded data, the capacity of the optical fiber cable and 100BASE-FX signal band, maximum 11, $154 \sim 5,818$ number of building FDA can be added. The most advancement in this proposed network is that any change in the network can be edited easily by changing the FDA's network address.

\section{Performance Comparison}

Finally it is important to observe the performance of the proposed system with the existing networks. For this comparison, we have added the time consumption results of existing popular networks known as Mobile/GSM ${ }^{17}$, Conventional cable ${ }^{51}$ and web-based FDA system. From the comparison, the proposed algorithm (yellow marked) showing better performance than other well-known networking systems. Figure 11 shows the bar graph comparison of the networks.

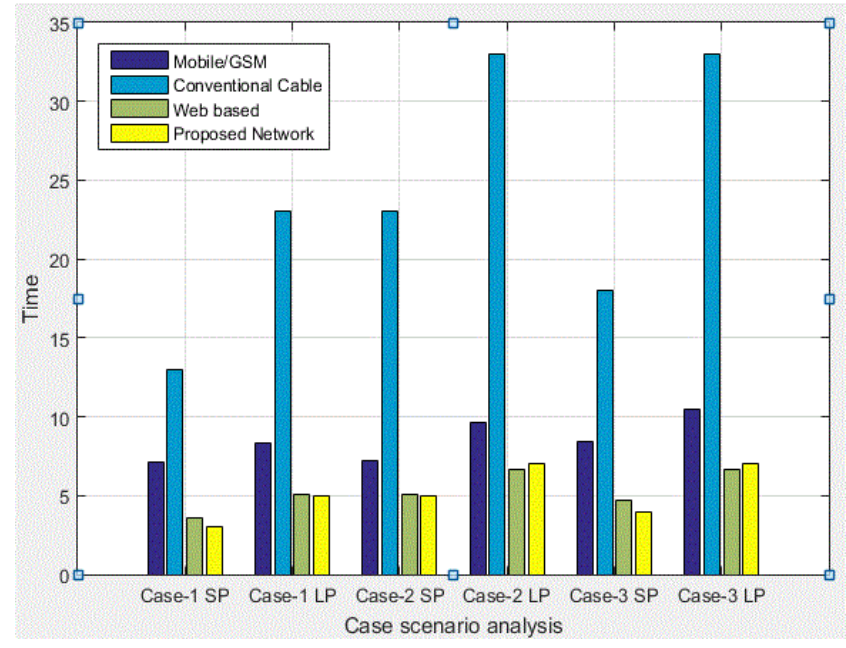

Figure 11. Performance analysis of the proposed system with existing popular systems $\frac{17,51}{}$.

\section{Conclusion and Future Work}

To conclude, in this work, an advanced FDA system is designed based on a robust network technology and tested with simulated network architecture. The simulation process showed an expected performance while working in proposed network topology to send an alarm 
to the central control room. In this system, it is required to place the fire detection location according to the arrangement of the distributed networking system as building site to analyze its performance. But, for the lab test building localization mechanism is considered with virtual device connection process. Therefore, the virtualization of designed workload makes the system appear more robust than usual. Therefore it requires further tests with a more realistic scenario to ensure its fire protection capability and to compare the efficiency of other systems. To improve the fire detection systems of the buildings, we will also focus on control automated solution of predicting the fire behavior efficiently.

\section{Acknowledgement}

The Authors express their personal appreciation for the effort of Saiyara Shehnaz in proof-reading the paper. The authors gratefully acknowledge the financial support of IIUM Research Management Center (RMC) and Ministry of Higher Education Malaysia under Research Initiative Grant Scheme (RIGS) number RIGS16-084-0248.

\section{References}

1. Lee KC, Lee HH. Network-based fire detection system via controller area network for smart home automation, IEEE Transactions on Consumer Electronics. 2004 Nov; 50(4):1093-100. Crossref.

2. Kim JS, Lyou J. The communication method at the autostartup systems using TCP/IP and VXI and expert system (g2), International Journal of Control, Automation and Systems. 1999 Dec; 1(2):141-46.

3. Suh SH, Woo KJ. Serial communication based fault diagnosis of a BLDC motor using bayes classifier, International Journal of Control, Automation, and Systems. 2013; 9:308-14.

4. Silentknight. Date accessed: 12/02/2016. http://www.silentknight.com/pages/default.aspx.

5. Simplexgrinnell. Date accessed: 11/09/2017. http://www. simplexgrinnell.com.

6. Notifier. Date accessed: 20/05/2017. http://www.notifier. com.

7. Miyagi PE. Petri net approach for modelling system integration in intelligent buildings, Journal of the Braziliansociety of Mechanical Sciences. 2002; 23(4):341-50. Crossref.

8. Fanger OP. Human requirements in future air-conditioned environments, International Journal of Refrigeration. 2001; 24(2):148-53. Crossref.
9. Korea fire industry technology institute model approval and inspection technical standards for fire detectors. National Emergency Management Agency in South Korea; 2011.

10. Bukowski RW. Moorewdfire alarm signaling systems. 3rd Ed. Nfpainc; 2003. p 31-252.

11. Fire alarm system. Date accessed: 15/11/2017. http:// en.wikipedia.org/wiki/fire_alarm_system.

12. Fire alarm control panel. Date accessed: $1 / 11 / 2017$. http:// en.wikipedia.org/wiki/fire_alarm_control_panel.

13. Liu ZG, Makar JM, Kim KA. Development of fire detection systems in the intelligent building. National Research Council of Canada; 2001. p. 561-73.

14. Liyang Y, Wang N, Meng X. Real-time forest fire detection with wireless sensor networks, Wireless Communications Networking and Mobile Computing Proceedings International Conference. 2005; 2:1-4.

15. Wang Y, Yu C, Tu R, Zhang Y. Fire detection model in Tibet based on grey-fuzzy neural network algorithm, Expert Systems with Applications. 2011; 38(8):9580-86. Crossref.

16. Krammer L, kastner W, Sauter T. A generic dependability layer for building automation networks. In: Factory Communication Systems IEEE World Conference; 2016. p. $1-4$.

17. Steenberg CM, Duijn VN. Patent and trademark office review; 2014. p. 1-116.

18. Bhatt J, Verma HK. Design and development of wired building automation systems, Energy and Buildings. 2015; 103:396-413.

19. Gangurde SS, Tated KS. Zigbee based wireless fire security node design using FPGA whose monitoring and controlling through labview, Journal of Analog and Digital Devices. 2016; 1-2.

20. Ma j, Yang X, Wang P. Design of the intelligent smoke alarm system based on photoelectric smoke. In: Second International Conference on Photonics and Optical Engineering; 2017. p. 1025623.

21. Somov A, Baranov A, Spirjakin D. A wireless sensoractuator system for hazardous gases detection and control, Sensors and Actuators a: Physical. 2014; 210:157-64.

22. Mary GL, Alex ZC, Jenkins L. Time analysis of wireless controller area network-based fire and gas safety system, International Journal of Communication Networks and Distributed Systems. 2017; 18(1):1-17. Crossref, Crossref.

23. Pan Z, Hariri S, Al-nashif Y. Anomaly based intrusion detection for building automation and control networks. In: Computer Systems and Applications 11th International Conference; 2014. p. 72-77. Crossref.

24. Bharani JC, Gowtham M, Nrmada K, Prasath JR. Fire rescue system in railways using labview. In: Green Computing Communication and Electrical Engineering International Conference; 2014. p. 1-13. 
25. Islam MA, Islam MM. A novel signature-based traffic classification engine to reduce false alarms in intrusion detection systems, International Journal of Computer Networks and Communications. 2015; 7(1):1-63.

26. Mcneil JG, Lattimer BY. Autonomous fire suppression system for use in high and low visibility environments by visual servoing, Fire Technology. 2016; 52(5):1343-68. Crossref.

27. Kim JH, Jattimer BY. Real-time probabilistic classification of fire and smoke using thermal imagery for intelligent firefighting robot, Fire Safety Journal. 2015; 72:40-49. Crossref.

28. Djahel S, Doolan R, Muntean GM, Murphy J. A communications-oriented perspective on traffic management systems for smart cities: challenges and innovative approaches, IEEE Communications Surveys and Tutorials. 2015; 17(1):125-51. Crossref.

29. Chen L, Zhou Q, Fang W. Spatial pyramid pooling in structured sparse representation for flame detection. In: Proceedings of the International Conference on Internet Multimedia Computing and Service; 2016 Aug. p. 310-13.

30. Fang W, Zhen Y, Kang QS, Xi, SD, Shang LY. A simulation research on the visual servo based on pseudo-inverse of image jacobian matrix for robot, Applied Mechanics and Materials Transaction Technology Publications; 2014; 1(494):1212-15.

31. Deve KB, Hancke GP, Silva BJ. Design of a smart fire detection system. In: Industrial Electronics Society, Ieconannual Conference of the IEEE; 2016. p. 6205-10.

32. Di Pasquale F, Soto MA, Bolognini G. Raman based distributed optical fiber temperature sensors: Industrial applications and future developments. World scientific publishing co. Private. Ltd.; 2014. p. 88-113.

33. Sun M, Tang Y, Yang S, Li J, Sigrist MW, Dong F. Fire source localization based on distributed temperature sensing by a dual-line optical fiber system, Sensors. 2016; 16(6):1-829. Crossref, Crossref, Crossref, Crossref, Crossref, Crossref, Crossref.

34. Peto R. US Patent and trademark office. Fiscal Year Congressional Justification; 2016. p. 1-158. PMid: 27809956 PMCid:PMC5107885.

35. Ziemann O, Krauser J, Zamzow PE, Daum W. Pof-polymer optical fibers for data communication. Springer Science and Business Media; 2013. p. 1-436. PMid: 23993679.

36. Decusatis C. Handbook of fiber optic data communication: A practical guide to optical networking. Academic Press; 2013. p. 1-468.

37. Mahloo M, Chen J, Wosinska L. PON versus AON: Which is the best solution to offload core network by peer-to-peer traffic localization. Optical Switching and Networking; 2015. p. 15, 1-9.

38. Zhang N, Cheng N, Gamage AT, Zhang K, Mark JW, Chen $\mathrm{X}$. Cloud assisted hetnets toward $5 \mathrm{~g}$ wireless networks, IEEE Communications Magazine. 2015; 53(6):59-65. Crossref.
39. Zenon C, Fady A. Wireless sensor network based system for fire endangered areas. Third International Conference on Information Technology and Applications (ICITA'05); 2005. 2, p. 1.

40. Coors V. 3D-GIS in networking environments, Computers, Environment and Urban Systems. 2003; 27:345-57. Crossref.

41. Crooks A, Croitoru A, Stefanidis A, Radzikowski J. Earthquake: Twitter as a distributed sensor system. Transaction in GIS Geographic Information System; 2012. p. 1-26.

42. Shen W, Wang J, Han J. Entity linking with a knowledge base: issues, techniques, and solutions, IEEE Transactions on Knowledge and Data Engineering. 2015; 27(2):443-60. Crossref.

43. Rastogi M, Alvarado AS, Harris JG, Principe JC. Integrate and fire circuit as an ADC replacement in Proc. IEEE International Symposium on Circuits and Systems (ISCAS); 2011 May. p. 2421-24.

44. Feichtinger H, Principe J, Romero J, Alvarado A, Velasco G. Approximate reconstruction of band limited functions for the integrate and fire sampler, Advances in Computational Mathematics. 2012; 36:67-78. Crossref.

45. Prineas RJ, Crow RS, Zhang Z. The Minnesota code manual of electrocardiographic findings. 2nd Ed. London, UK Springer-Verlag; 2010. p. 1-5. Crossref, Crossref.

46. Tang K, Yao X. Special issue on Nature inspired problem solving, Information Sciences. 2008 Aug; 178(15):2983-84. Crossref.

47. Yahiaoui AJ, Hensen L, Soethout DVP. Design of embedded controller using hybrid systems for integrated building systems. In: International SCRI Symbiposis Center for Research Innovation; 2006. p. 1-10. PMCid: PMC1698076.

48. D’Orazio MA, Sauro Longhi B, Olivetti PA, Bernardin G. Design and experimental evaluation of an interactive system for pre-movement time reduction in case of fire; 2015. p. 52.

49. Kady RA, Davis J. The impact of exit route designs on evacuation time for crawling occupants, Journal Fire Science. 2009; 27(2009):481-93. Crossref.

50. Tabirca T, Brown KN, Sreenan CJ. A dynamic model for fire emergency evacuation based on wireless sensor networks. Eighth International Symposium on Parallel and Distributed Computing; 2009. p. 29-36. Crossref.

51. Imtiaz WA, Iqbal J, Qamar A, Ali H, Idrus SM. Impact of fiber duplication on protection architectures feasibility for passive optical networks. In: Optical Fiber and Wireless Communications International Techonolgy; 2017. Crossref.

52. Asif O, Hossain MB, Hasan M, Rahman MT, Chowdhury ME. Fire-Detectors Review and design of an automated, quick responsive fire-alarm system based on SMS, International Journal of Communications, Network and System Sciences. 2015; 7(09):1-389. 